\title{
Application of Image Analysis Tools in Matlab to Better Estimate the Degree of Binder Coverage in Rolling Bottles Test.
}

Syed Bilal Ahmed Zaidi ${ }^{(1)}$, Gordon Airey ${ }^{(2)}$, James Grenfell ${ }^{(3)}$, Naveed Ahmad ${ }^{(1)}$, Imtiaz Ahmed $^{(2)}$ and Ahmed Abed ${ }^{(2)}$

1. Taxila Institute of Transportation Engineering, University of Engineering and Technology, Taxila

2. Nottingham Transportation Engineering Centre, University of Nottingham, Nottingham, UK

3. ARRB, Australian Road Research Board, VIC, Australia

\begin{abstract}
In asphalt mixture, a strong affinity between binder and aggregates is of prime importance, especially under conditions susceptible for moisture damage. To improve this affinity between binder and aggregates various additives and modifiers have been identified by the researchers across the globe. Among all the available additives or modifiers, hydrated lime has been reported as one of the best, which can be used to enhance the affinity between bitumen and aggregates. This study attempts to quantify the affinity of hydrated lime modified mastics with different aggregates under moisture conditions. Various techniques are available for the affinity assessment between binder and aggregates, with the rolling bottle test (RBT) reported as one of the best empirical techniques which is used worldwide. In the RBT test the assessment for affinity is made through visual inspection by two experienced operators as per a standard procedure which can also be the major drawback of this technique. An effort has been made to reduce this deficiency in the method and to make the RBT a more reliable and repeatable means of measuring the affinity between aggregate and binder in the presence of water. This has been done using image analysis techniques with no special setup, employing the Matlab program. The results after image analysis were compared to the results of visual observation and both were found to be very similar to each other. Hence the RBT can now be used confidently for the comparison of different binder/aggregate combinations. The beneficial effects of HL addition were clearly quantified with
\end{abstract}


granite, basalt and greywacke aggregates, but limestone aggregates did not respond to the effect of HL addition when tested in the RBT. Based on the results of the RBT test, $10 \%$ HL substitution was found to be more efficient than a $20 \% \mathrm{HL}$ substitution, which gave very similar results to $10 \%$ HL substitution in most of the studied combinations.

Keywords: Affinity, hydrated lime, rolling bottle test, image analysis, Matlab

\section{Introduction}

The rolling bottle test as per BS EN 12697-11 [1], is a measure of affinity between aggregate and bitumen and also measures the susceptibility to stripping. The susceptibility to stripping gives an indirect indication of the bond strength between the binder and the aggregate. This procedure can also be used to evaluate the effect of moisture for a given binder and aggregate combination as the loose bitumen coated aggregates are agitated in water for a certain period of time. The results are usually measured by visual inspection in terms of the degree of bitumen coating on loose aggregates after the influence of mechanical stirring in water.

There are many techniques which are used to quantify the affinity between binder and aggregates. Airey, Choi [2], [2][2]in a state of the art report on moisture sensitivity test methods for pavement materials summarised 10 different methods on loose coated aggregates to quantify this affinity in the presence of water. It is difficult to pick the best method out of all, as each have their advantages and disadvantages. Jorgensen [3] compared boiling water and rolling bottle tests during a round-robin study and found that the boiling water test can be used differentiate between good and bad combinations of binder and aggregates, but on the other hand the rolling bottle test can be used to rank these combinations, and hence is more precise and reliable. Another comparative study was made by Liu et al. [4] considering five empirical tests on loose mixtures for performance evaluation including the static immersion test, rolling bottle test (RBT), boiling water test (BWT), total water immersion test and the ultrasonic method. Surface free energy (SFE) tests on aggregate and bitumen were also performed to correlate the performance with these empirical methods. The RBT and BWT were found to be the most sensitive procedures among the five empirical procedures in predicting 
moisture damage performance. The mixture ranking given by RBT was found to be in agreement with the results of SFE testing. Based on the findings of the previous studies using RBT, it can be said that it is one of the most efficient empirical procedures for moisture damage assessment.

Following the standard procedure, the rolling bottle test measures the affinity between the aggregates and bitumen. It does this by assessing the percentage of binder coating on loose aggregates using visual inspection by two experienced operators and takes the average value of the two observations to the nearest $5 \%$. Sometimes it is not possible to get two operators at the required time or sometimes even if two are available there is a big difference in the values they suggest. People can consider the results biased as they are based on visual inspection. Many researchers [5-8], have a view that as RBT results are based on visual inspection, so are they very subjective and this is one of the drawbacks of the test method. In some recent studies, attempts have been made to replace eye observation with the digitally processed images using different software like Image $\mathbf{J}$ and Image Pro Plus. However, the problem is that one has to make special arrangements for image capturing, including enhanced lighting and placement of aggregate on a special platform during image capture $[9,10]$.

In this research, an effort has been made to reduce the disadvantages of the method and to make the RBT a more reliable and repeatable means of measuring the affinity between aggregate and binder in the presence of water, using image analysis techniques with no special setup, employing the Matlab program.

\section{Materials}

Aggregates from four different sources in UK have been selected for this research. These were a limestone, a granite, a basalt and a greywacke. The basic properties of the aggregates used are presented in Table 1. 
Table 1: Physical characteristics of the crushed aggregate

\begin{tabular}{|l|l|l|}
\hline Aggregate Type & $\begin{array}{l}\text { Particle density } \\
\left(\mathrm{Mg} / \mathrm{m}^{3}\right)\end{array}$ & $\begin{array}{l}\text { Water absorption } \\
(\%)\end{array}$ \\
\hline Granite & 2.77 & 0.40 \\
\hline Limestone & 2.70 & 1.20 \\
\hline Basalt & 2.96 & 2.41 \\
\hline Greywacke & 2.80 & 0.90 \\
\hline
\end{tabular}

As filler type affects asphalt mixture properties significantly, five fillers have been identified to be used, namely limestone, granite, greywacke, basalt and hydrated lime (HL). As this study focuses on the effect of HL on the performance of asphalt mixture, the four filler types i.e. limestone, granite, basalt and greywacke, were used with their parent aggregate type and HL was used as a replacement in certain percentages within the mastic.

To qualify the effect of HL it can either be added in the bitumen to make a mastic or can be added to the aggregate to form a mixture. In this research, the first method has been used. The addition of HL in the neat bitumen to make mastic can be justified by previous research as to better comprehend the properties of asphalt mixtures. Numerous researchers have utilised intermediate materials, for example, mastics, i.e. mixes of just bitumen and filler, as a model framework [11-13]. The thought behind this methodology is that the material sticking together the aggregates inside the mixture is not the bitumen only but is the bitumen mixed with the finest components of the mineral aggregate, called 'filler' [14].

Table 2: Properties of 40/60 bitumen used in the study

\begin{tabular}{|l|c|l|}
\hline Property & Value & Standard \\
\hline Specific Gravity & 1.03 & BS 2000-549 [15] \\
\hline $\begin{array}{l}\text { Penetration Index at } \\
25^{\circ} \mathrm{C}\end{array}$ & 45 & BS EN 1426 [16] \\
\hline Softening Point $\left({ }^{\circ} \mathrm{C}\right)$ & 50 & BS 2000-58 [17] \\
\hline
\end{tabular}


Table 3: Summary of mastics notation, composition and type of aggregate used in combination

\begin{tabular}{|c|c|c|c|}
\hline $\begin{array}{l}\text { Serial } \\
\text { No. }\end{array}$ & $\begin{array}{l}\text { Mastic } \\
\text { Notation }\end{array}$ & Composition & $\begin{array}{l}\text { Used in } \\
\text { combination with } \\
\text { Aggregate type }\end{array}$ \\
\hline 1 & $50 \% \mathrm{G}$ & $\begin{array}{l}50 \% \text { granite filler }+50 \% 40 / 60 \\
\text { pen neat bitumen }\end{array}$ & Granite \\
\hline 2 & $\begin{array}{l}40 \% \mathrm{G}+10 \% \\
\mathrm{HL}\end{array}$ & $\begin{array}{l}40 \% \text { granite filler }+10 \% \\
\text { Hydrated lime }+50 \% \quad 40 / 60 \\
\text { pen neat bitumen }\end{array}$ & Granite \\
\hline 3 & $\begin{array}{l}30 \% \mathrm{G}+20 \% \\
\mathrm{HL}\end{array}$ & $\begin{array}{l}30 \% \text { granite filler }+20 \% \\
\text { Hydrated lime }+50 \% \quad 40 / 60 \\
\text { pen neat bitumen }\end{array}$ & Granite \\
\hline 4 & $50 \% \mathrm{LS}$ & $\begin{array}{l}50 \% \text { limestone filler }+50 \% \\
40 / 60 \text { pen neat bitumen }\end{array}$ & Limestone \\
\hline 5 & $\begin{array}{l}40 \% \mathrm{LS}+10 \% \\
\mathrm{HL}\end{array}$ & $\begin{array}{l}40 \% \text { limestone filler }+10 \% \\
\text { Hydrated lime }+50 \% 40 / 60 \\
\text { pen neat bitumen }\end{array}$ & Limestone \\
\hline 6 & $\begin{array}{l}30 \% \mathrm{LS}+20 \% \\
\mathrm{HL}\end{array}$ & $\begin{array}{l}30 \% \text { limestone filler }+20 \% \\
\text { Hydrated lime }+50 \% \quad 40 / 60 \\
\text { pen neat bitumen }\end{array}$ & Limestone \\
\hline 7 & $50 \% \mathrm{~B}$ & $\begin{array}{l}50 \% \text { basalt filler }+50 \% 40 / 60 \\
\text { pen neat bitumen }\end{array}$ & Basalt \\
\hline 8 & $\begin{array}{l}40 \% \mathrm{~B}+10 \% \\
\mathrm{HL}\end{array}$ & $\begin{array}{l}40 \% \text { basalt filler }+10 \% \\
\text { Hydrated lime }+50 \% \quad 40 / 60 \\
\text { pen neat bitumen }\end{array}$ & Basalt \\
\hline 9 & $\begin{array}{l}30 \% \mathrm{~B}+20 \% \\
\mathrm{HL}\end{array}$ & $\begin{array}{l}30 \% \text { basalt filler }+20 \% \\
\text { Hydrated lime }+50 \% \quad 40 / 60 \\
\text { pen neat bitumen }\end{array}$ & Basalt \\
\hline 10 & $50 \% \mathrm{GW}$ & $\begin{array}{l}50 \% \text { greywacke filler }+50 \% \\
40 / 60 \text { pen neat bitumen }\end{array}$ & Greywacke \\
\hline 11 & $\begin{array}{l}40 \% \mathrm{GW}+10 \% \\
\mathrm{HL}\end{array}$ & $\begin{array}{l}40 \% \text { greywacke filler }+10 \% \\
\text { Hydrated lime }+50 \% \quad 40 / 60 \\
\text { pen neat bitumen }\end{array}$ & Greywacke \\
\hline 12 & $\begin{array}{l}30 \% \mathrm{GW}+20 \% \\
\mathrm{HL}\end{array}$ & $\begin{array}{l}30 \% \text { greywacke filler }+20 \% \\
\text { Hydrated lime }+50 \% \quad 40 / 60 \\
\text { pen neat bitumen }\end{array}$ & Greywacke \\
\hline
\end{tabular}

Each aggregate type has been tested with four combinations of binders including one neat bitumen (40/60 pen) and three mastics (Table 3 ). The properties of base bitumen used in this study were shown in

Table 2. In total 12 different types of mastics have been used in combination with four types of aggregates. The notation, composition and the type of the aggregate with which these mastics have been used are presented in Table 3.

\section{Test Method}


The rolling bottle Test (RBT) has been conducted in accordance with BS EN 1269711 [1]. It is a measure of the affinity between aggregate and bitumen. This affinity is measured by visual inspection in terms of the degree of bitumen coating on loose bitumen coated aggregates after the influence of mechanical stirring in water. Clean and fully dried aggregate particles are coated with an approximately $0.1 \mathrm{~mm}$ thick layer of bitumen. These coated aggregates are then stored at room temperature for 12 to 64 hours before testing. For testing, glass bottles are filled to approximately the shoulder with deionised water, binder coated aggregates and a glass stirrer. The bottles are rotated at a speed of 60 rotations per minute for a total of 72 hours. At the end of the first six hours the samples are emptied from the glass bottles and placed in a test bowl which is then filled with fresh water and the percentage of bitumen coating on the aggregate particles is recorded visually to the nearest $5 \%$. This procedure is repeated at the end of 24,48 and 72 hours and the degree of bitumen coating is estimated. At the end, the mean value is taken to get an average bitumen coating on the aggregates. Along with the observation with the naked eye, good quality images have been taken for each combination used in this study. An internally produced code has been developed in Matlab software to analyse the images. For analysis in Matlab, each image has been divided into three components i.e. bitumen or mastic, aggregates and background.

To get the percentage coating on the aggregates, first the background was eliminated from the image. Afterwards, the remaining area was termed as the 'total area'. From this 'total area', the percentage of bitumen/mastic coated aggregates was calculated and rounded to the nearest $5 \%$. There were three variables in the code. One was the pixel's threshold limit for the aggregates coated with bitumen called bitumen upper limit (bul). The second was the pixel's threshold value for the aggregates without any bitumen coating called aggregate upper limit (aul) and the third was the threshold limit for the background to be eliminated from the full image.

These three variables need to be changed from image to image for analysis purposes as the picture quality may be different among all the images. There are different factors contributing to the variable quality among the different images which include;

- The distance from which each picture was taken. 
- The angle from which the picture was taken

- The difference of brightness in the room at different times

- Image resolution, if taken with multiple devices.

The ideal case would be to capture all the images at the same distance and to keep the capturing device as flat as possible on the top of the sample. Light in the room is also very important, it should not be too bright nor too dim to get the best image and one should make an effort to keep light intensity as uniform as possible throughout the image capturing.

It is difficult to observe all the above conditions at once and sometimes it is not possible or practical and that is why provisions have been made in the code to accommodate these variabilities.

Keeping in mind all the above-mentioned precautions, quality images have been taken after 6, 24, 48 and 72 hours of agitation in the RBT for all the aggregates and bitumen/mastic combinations. After the acquisition of quality images, the percentage of bitumen/mastic coating has been calculated using the code as previously discussed.

Images before and after processing with the Matlab program are shown in

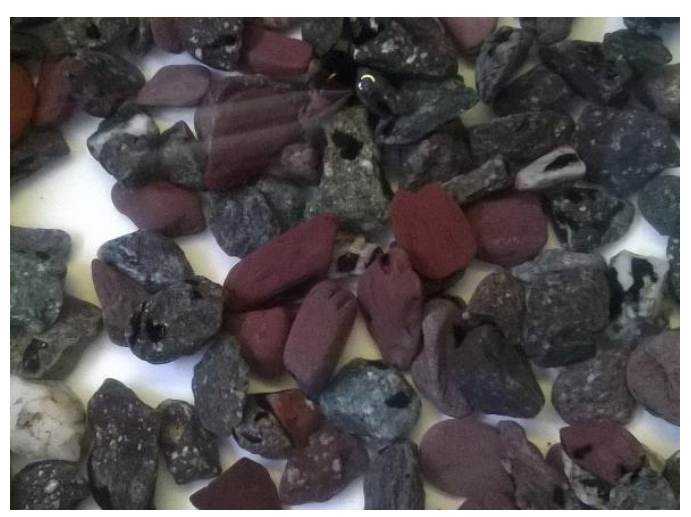

Granite after 72 Hour without Image analysis

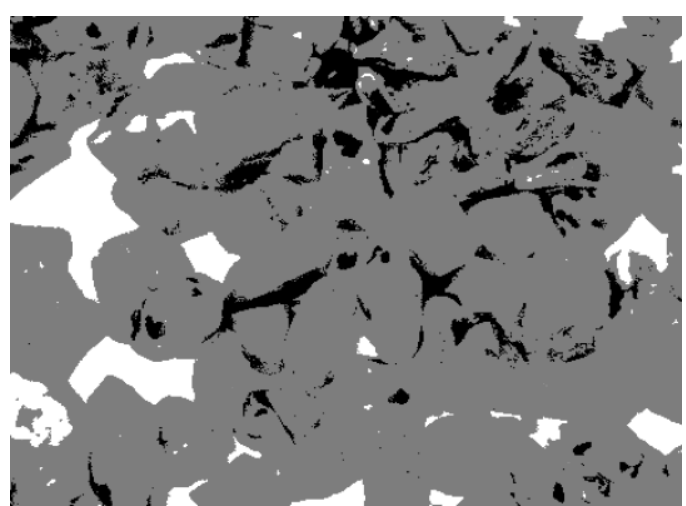

Granite after 72 Hour with Image analysis 


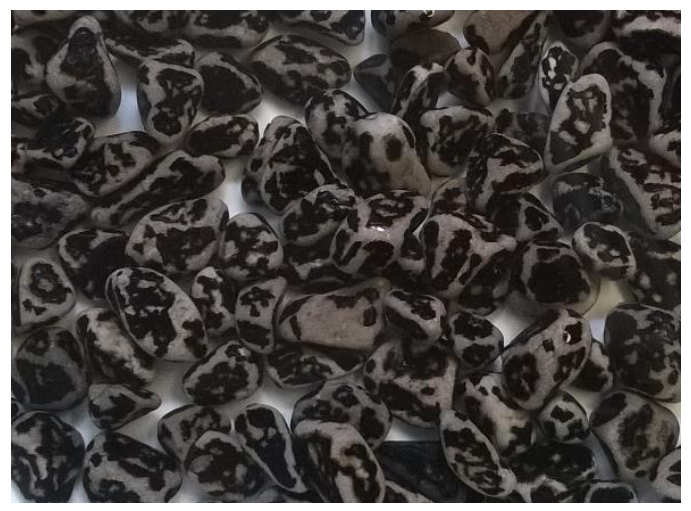

Limestone after 72 Hour without Image analysis

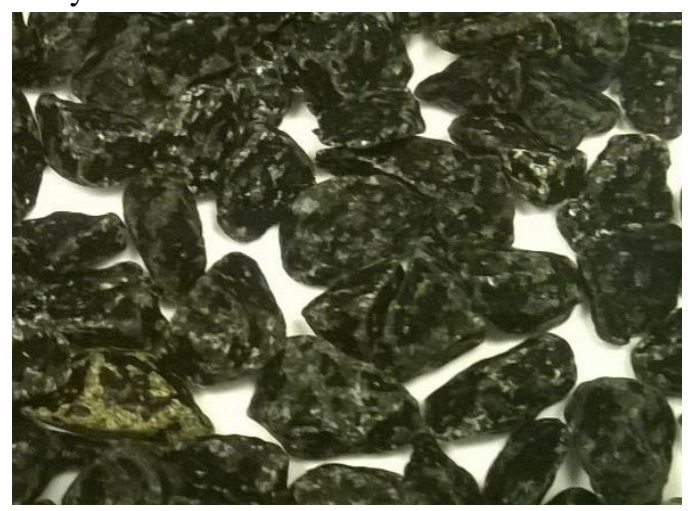

Basalt after 72 Hour without Image analysis

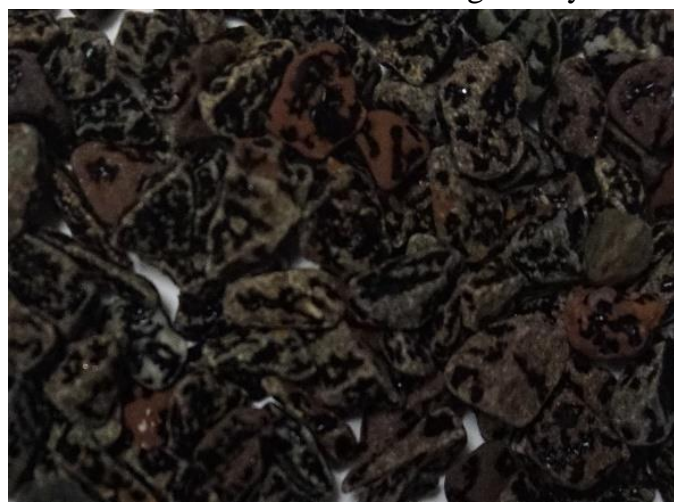

Greywacke after 72 Hour without Image analysis

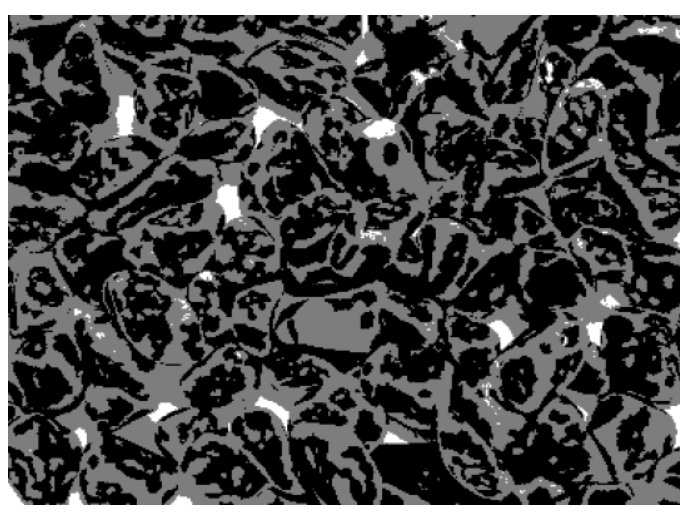

Limestone after 72 Hour with Image analysis

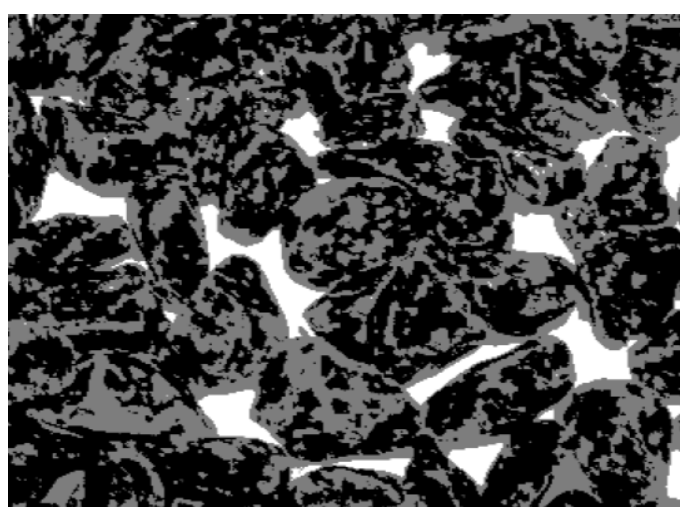

Basalt after 72 Hour with Image analysis

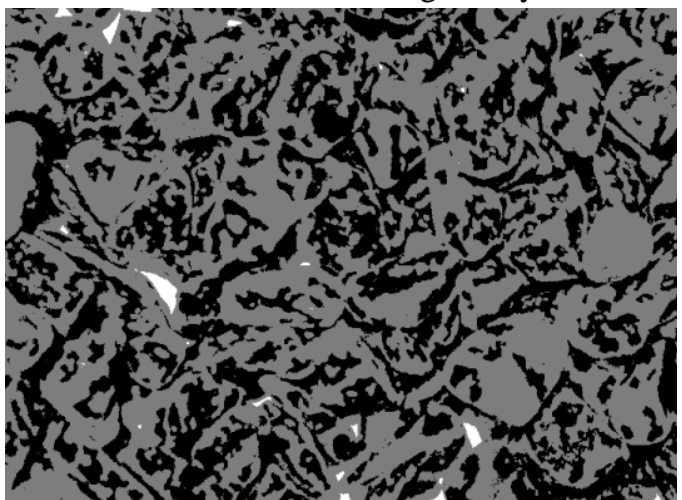

Greywacke after 72 Hour with Image analysis

Figure 1 to illustrate how the processed image will look and how the background, bitumen coating and aggregate surfaces have been divided. These are the images for neat bitumen in combination with different types of aggregates used in this study, after 72 hours of agitation in the RBT. The white portion of the processed image represents the background which has been excluded from the total area. The grey portion shows aggregates without any bitumen coating and the black portion is the bitumen-coated aggregates. A percentage area of the aggregates coated with bitumen has been recorded as the final result. 


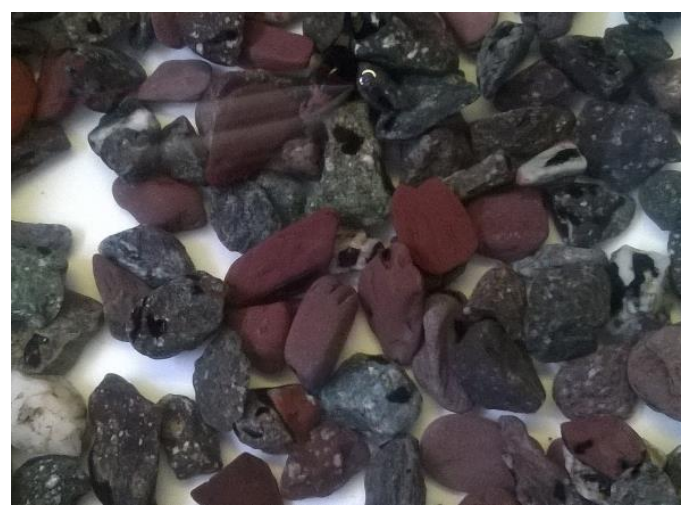

Granite after 72 Hour without Image analysis

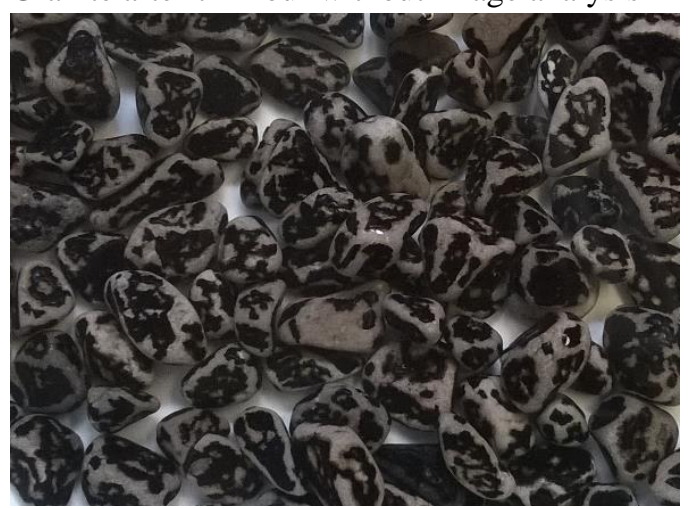

Limestone after 72 Hour without Image

analysis

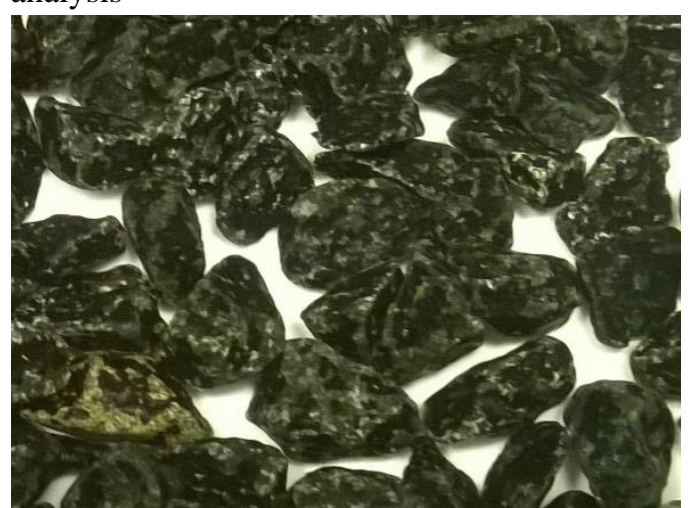

Basalt after 72 Hour without Image analysis

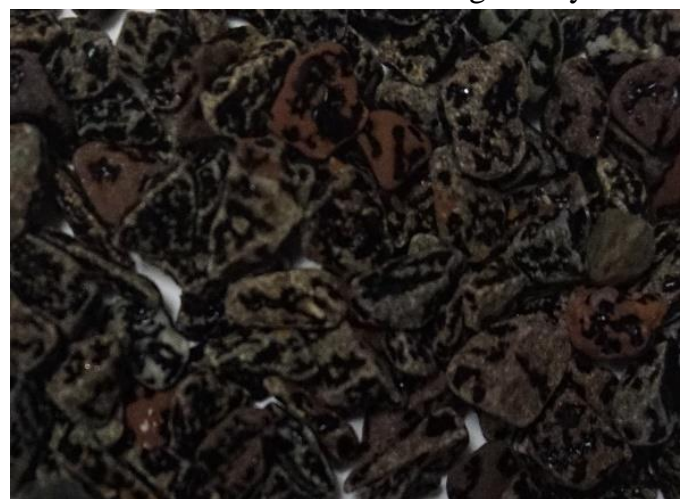

Greywacke after 72 Hour without Image analysis

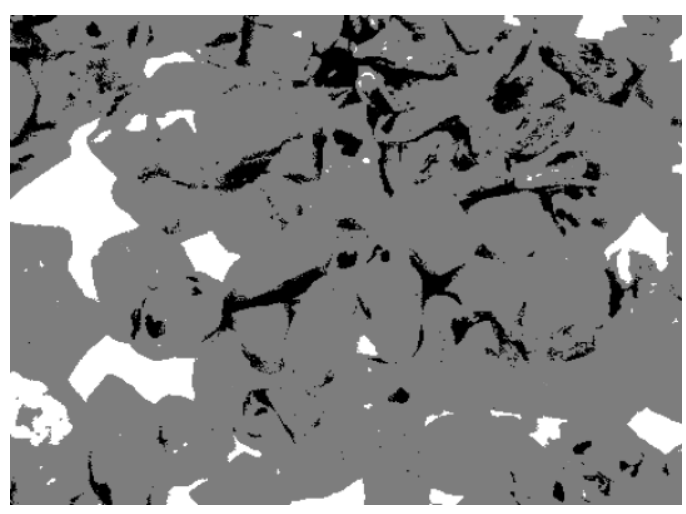

Granite after 72 Hour with Image analysis

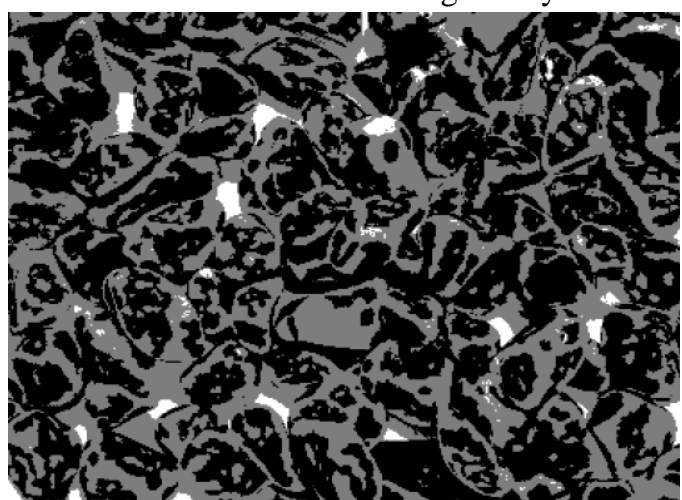

Limestone after 72 Hour with Image analysis

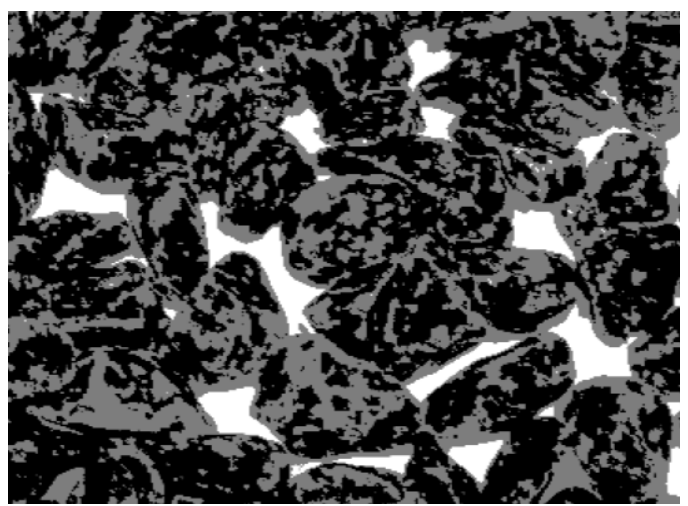

Basalt after 72 Hour with Image analysis

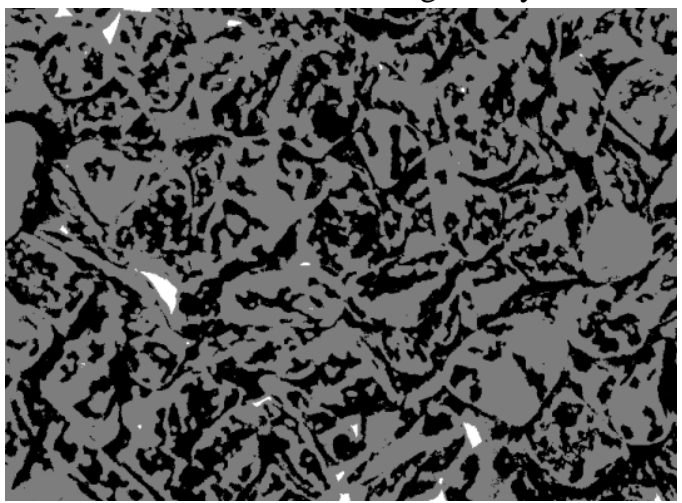

Greywacke after 72 Hour with Image analysis

Figure 1: Summary of images after 72 hours in the RBT before and after analysing with Matlab 


\section{Results and discussion}

The affinity between different aggregates and bitumen/mastic in the presence of moisture has been measured using the RBT as discussed earlier. Each of the studied combinations has been repeated twice and is found to be within $5 \%$ repeatability range. The allowable limits for the repeatability of the RBT as reported in BS EN 12697-11:2012 are 20\%, so the results of this research are well within that range and can be considered to have very good repeatability.

The results for granite aggregates and different combinations of bitumen/mastic are presented in Figure 2. From the figure it can be evaluated that with time, the coating of binder has decreased significantly especially for the 40/60 bitumen and for the mastic containing $0 \%$ hydrated lime $(50 \% \mathrm{G})$. For the mastics containing 10 and $20 \%$ hydrated lime, their retained percentage coating is considerably better than neat bitumen and the mastic with 0\% HL. Although the mastic with 20\% HL has shown slightly better results than the mastic with $10 \% \mathrm{HL}$, there is only a small difference between them.

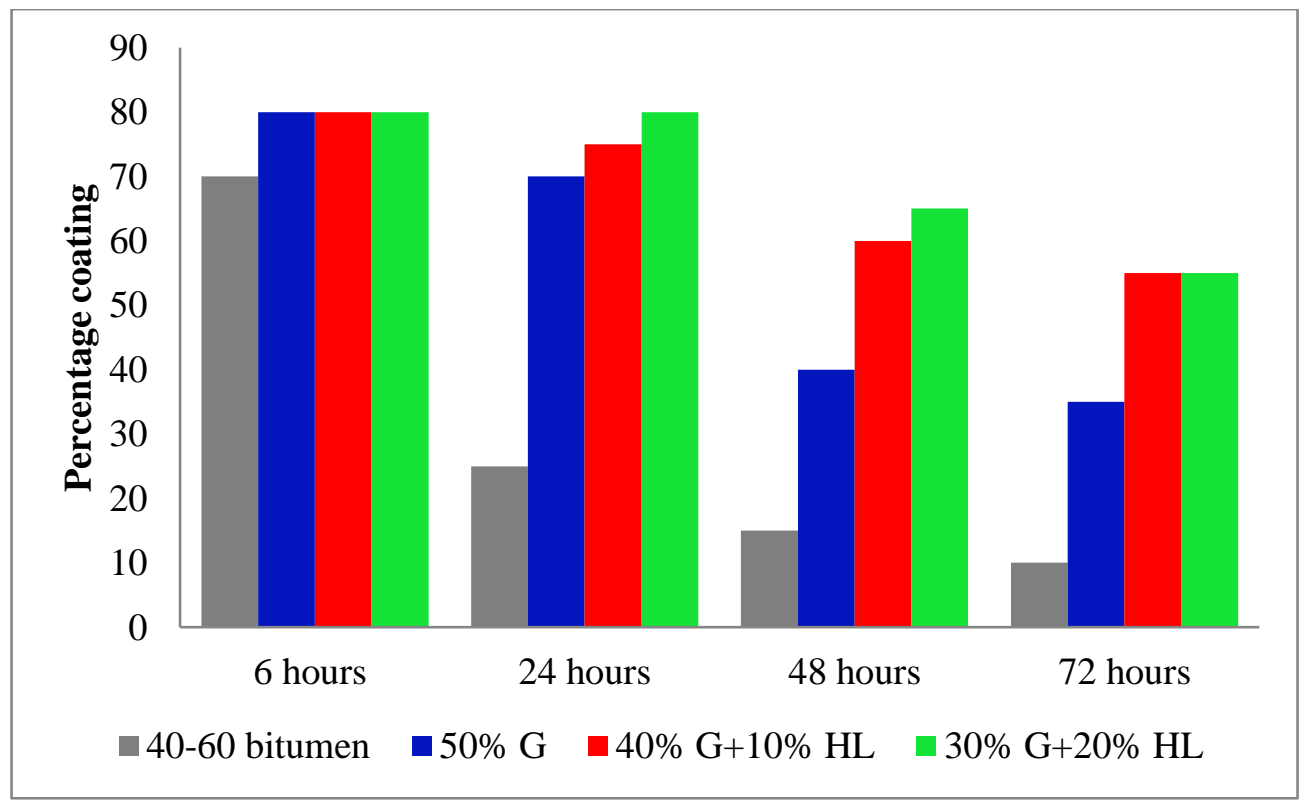

Figure 2: RBT test results for all combinations of granite aggregates using image analysis

Similarly, from Figure 3 for limestone aggregates there is no significant difference recorded between all the three mastics and 40/60 bitumen. In contrast to Figure 2, the mastic having $0 \%$ HL (50\% LS) performs slightly better than those containing $10 \%$ and $20 \%$ HL. There 
is a marginal difference between neat bitumen and all three mastics used in combination with limestone aggregate. Based on these facts it can be concluded that hydrated lime does not seem to be beneficial in case of limestone aggregate.

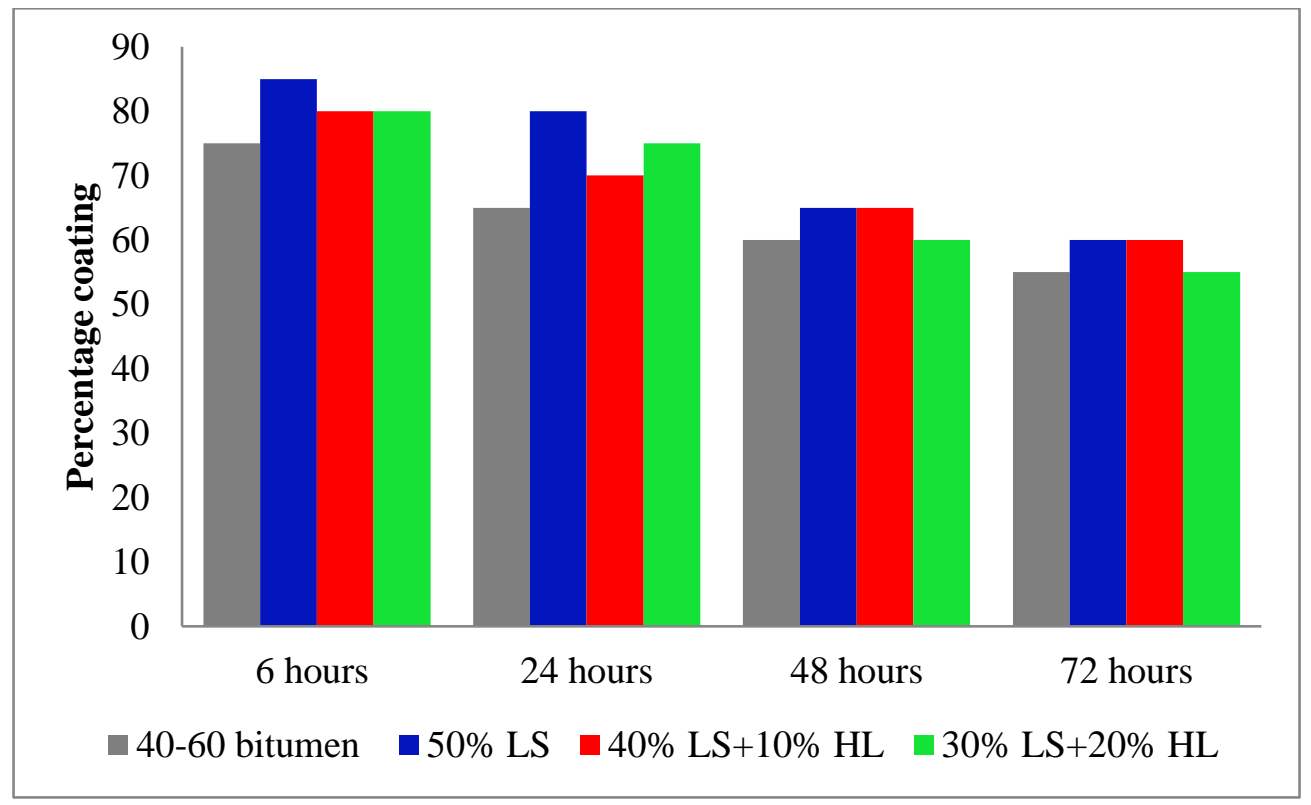

Figure 3: RBT test results for all combinations of limestone aggregates using image analysis

If we look at Figure 4 when basalt aggregate is used in combination with neat bitumen and the three mastic types, the beneficial effects of $\mathrm{HL}$ are obvious. Again, the performance of neat bitumen and the mastic with $0 \%$ HL (50\% Basalt) looks similar, but with the addition of $10 \%$ and $20 \% \mathrm{HL}$, the coating percentage remained at a higher level. It is worth noting that there is really no difference found between the performance of the mastics having $10 \% \mathrm{HL}$ and $20 \% \mathrm{HL}$ and both give good results in terms of higher affinity for aggregate compared to the mastic without HL. The results for the greywacke aggregates are summarised in Figure 5 and once again the beneficial effects of HL have been noted. Although the results are not as discriminatory as they were in the case of granite and basalt aggregates, there still has been a positive effect of HL addition noted clearly with the addition of $10 \%$ and $20 \%$ HL in comparison with neat bitumen and mastic with $0 \%$ HL. 


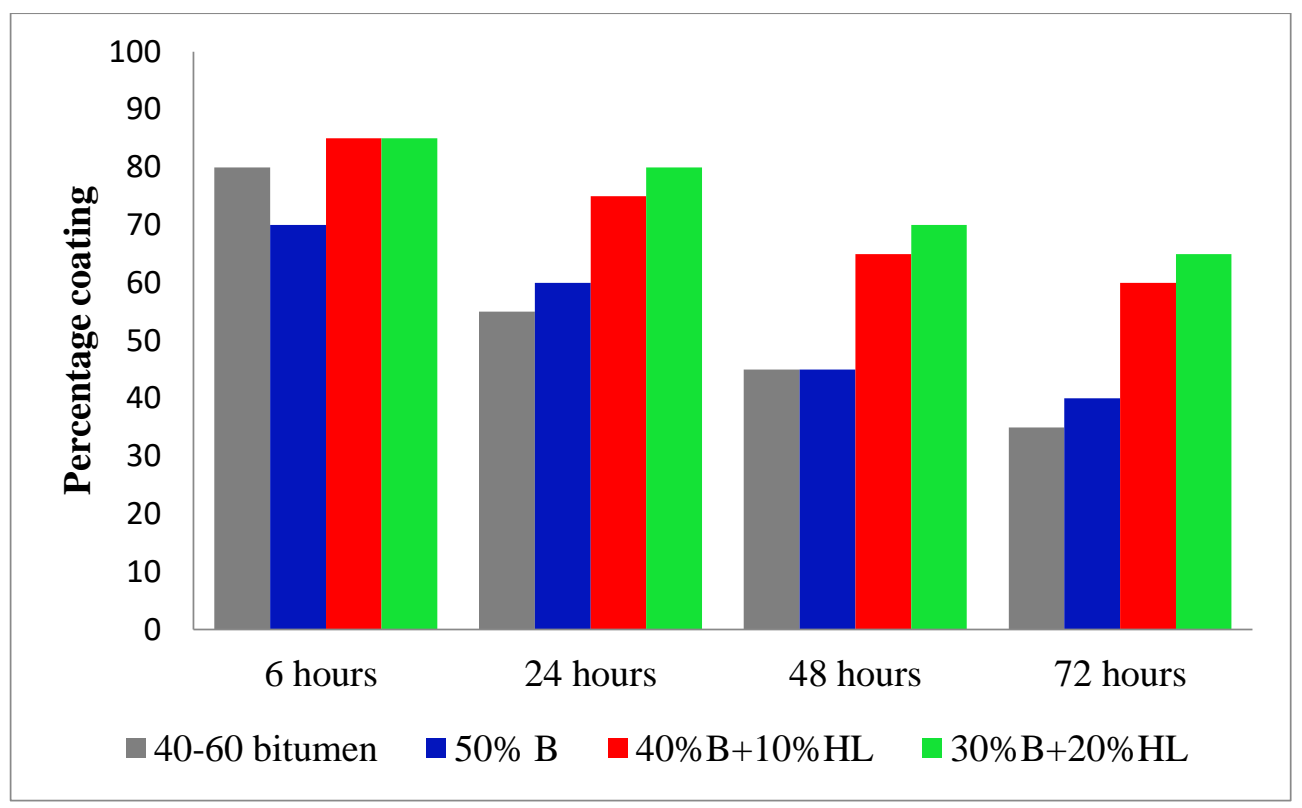

Figure 4: RBT test results for all combinations of basalt aggregates using image analysis

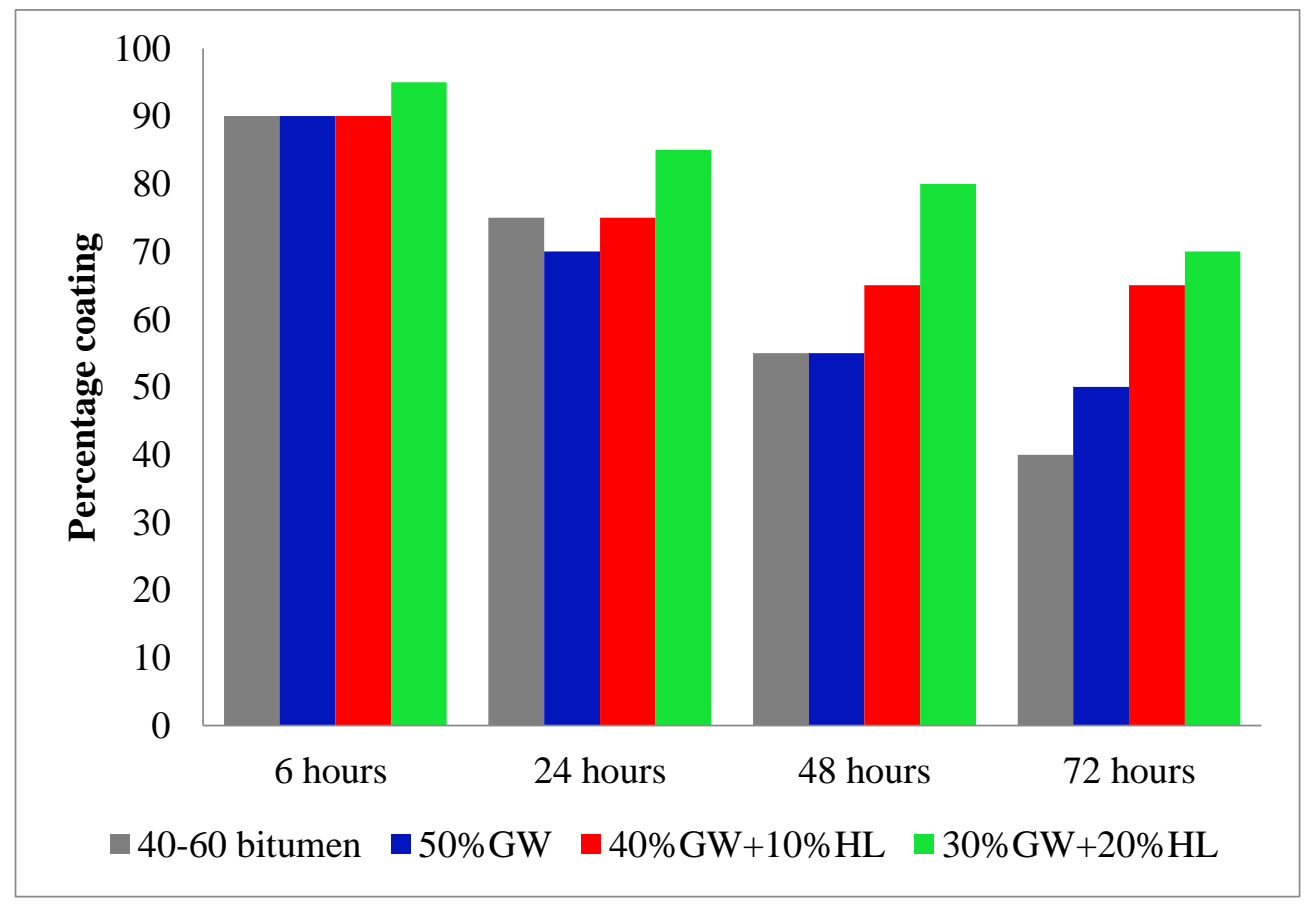

Figure 5: RBT test results for all combinations of greywacke aggregates using image analysis 
Looking at Figure 2-5 carefully, it is clear that there has been practically no difference between different combinations within the same aggregate type after 6 hours visual or photographic inspection of the samples. After 24 hours this difference is obvious in some of the aggregate types, for example in the case of granite aggregates the values for the percentage coating for neat bitumen, mastic with $0 \% \mathrm{HL}$, mastic with $10 \% \mathrm{HL}$ and mastic with $20 \% \mathrm{HL}$ are $25,70,75$ and $80 \%$ respectively. In the case of limestone aggregate, the percentage coating values at 24 hours for different combinations are not far from each other. The basalt aggregates showed a clear difference and with greywacke aggregates a small difference was observed after 24 hours.

Looking at the results after 48 hours of inspection, it can be seen that the granite aggregate shows more distinctive results between its different combinations. The values for percentage coating for neat bitumen, mastic with $0 \% \mathrm{HL}$, mastic with $10 \% \mathrm{HL}$ and mastic with $20 \% \mathrm{HL}$ are now 15, 40, 60 and $65 \%$ which is again more discriminatory compared to the 24 hour values. Again, limestone aggregates show nearly no difference between their various combinations. Basalt and greywacke results after 48 hours look similar to each other and both show clear differences between their various combinations. This difference is a bit more than what was seen after 24 hours.

The results after 72 hours of RBT agitation give the biggest difference between different combinations within the same aggregate type. For the granite aggregates, the values for percentage coating for neat bitumen, mastic with $0 \% \mathrm{HL}$, mastic with $10 \% \mathrm{HL}$ and mastic with $20 \% \mathrm{HL}$ are 10, 35, 55 and 55\% respectively. The values for limestone aggregates after 72 hours for its combination with neat bitumen, $50 \%$ LS, $40 \% \mathrm{LS}+10 \% \mathrm{HL}$ and $30 \% \mathrm{LS}+20 \% \mathrm{HL}$ are 55, 60, 60 and $55 \%$ respectively which is not very distinctive. Basalt aggregate in combination with neat bitumen, $50 \% \mathrm{~B}, 40 \% \mathrm{~B}+10 \% \mathrm{HL}$ and $30 \% \mathrm{~B}+20 \% \mathrm{HL}$ gave percentage coating values of $35,40,60$ and $65 \%$ respectively at 72 hours. Similarly, greywacke gave values of 40, 50, 65 and 70 for neat bitumen, 50\% GW, 40\% GW + 10\% HL and 30\% GW + $20 \%$ HL respectively.

Among all the aggregate types, the percentage coating for granite and basalt aggregate are the most distinctive. Greywacke also gives a significant effect with HL addition, but with limestone, on the other hand, HL does not show any effect, 
in fact all the combinations are similar to each other. This behaviour of HL with the limestone aggregates can be supported through the past research where it has been reported that hydrated lime has been found more effective in the asphalt mixtures having siliceous aggregate than limestone aggregates $[18,19,6]$

Now to compare the performance of the different aggregate types with and without HL, results after 72 hours have been summarised in Figure 6. The figure shows a clear difference between the performance of different aggregate types with their various combinations.

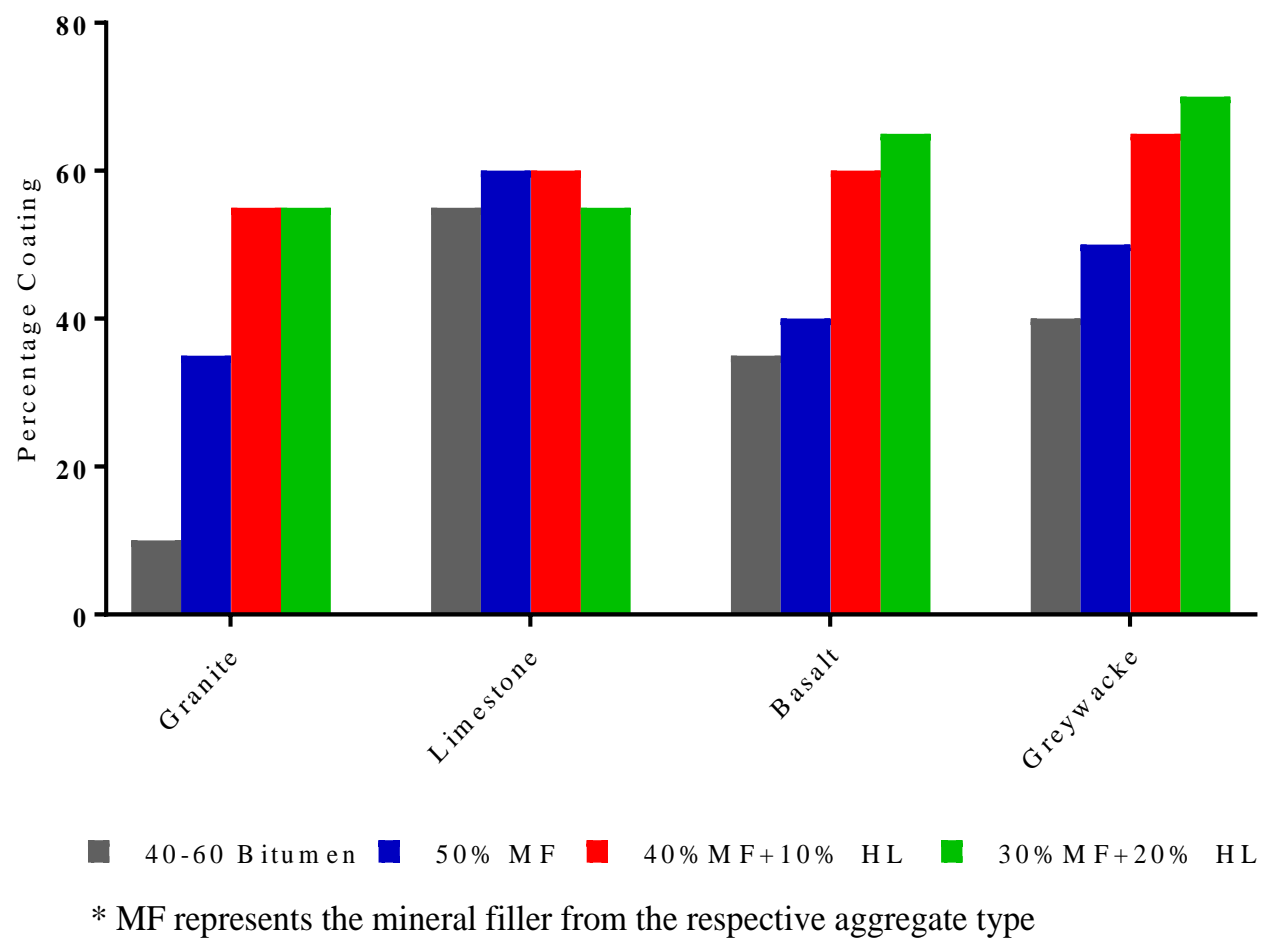

Figure 6: Comparison for RBT results after 72 hours between all aggregate combinations

Looking at the results of neat bitumen it can be found that it has the worst performance with granite aggregates. On the other hand, neat bitumen performance with the limestone is found to be the best compared to the other three types. Basalt and greywacke exhibit intermediate performance. Similarly, the mastic with 50\% mineral filler of the respective aggregate has shown quite variable performance, 
with the best performance that of limestone, then greywacke, basalt and again granite has the worst performance in comparison to all the aggregate types. With the addition of $10 \% \mathrm{HL}$ with the mineral filler, performance of some aggregate types has jumped to a significantly higher value. For example, the percentage coating for the granite aggregate has jumped to $55 \%$ compared to $35 \%$ without $\mathrm{HL}$ (50\% MF). Similarly, percentage coating increased by $50 \%$ in the case of basalt aggregate. For the limestone aggregate, there is a slight decrease observed with the addition of HL, but greywacke followed the same trend as the granite and basalt aggregates and showed an increase of $30 \%$ in coating with the addition of $10 \%$ HL. The performance of the mastics with $10 \%$ and $20 \%$ HL in most cases is very similar to each other. This means it may not be worth adding $20 \% \mathrm{HL}$ in the mastic as it does not improve the performance by the same amount as the $10 \%$ HL addition and the performance of the two mastics are very similar to each other in most cases.

Based on the discussion above it might be a good idea to check the coating left on the loose aggregates for time periods longer than 72 hours as the most discriminating stage was found to be at 72 hours in all the aggregate combinations in this particular test protocol.

\section{Comparison between visual observation and processed image results}

A comparison has been made for granite, limestone, basalt and greywacke aggregates in Tables 4-7, respectively between the observations made with the naked eye by the operators and results obtained after image analysis. The values for bitumen upper limit (bul) and aggregate upper limit (aul) have also been presented, which are used in the Matlab code for the calculation of percentage coating.

By looking at the above mentioned tables it can be seen that the results obtained from the naked eye and the results calculated after image analysis are very similar to each other. There will be some difference between the two results as one is just visual (subjective) observation and other is digitally computed using Matlab. The chance of error in the results computed using Matlab would be less compared to the observations made using the naked eye by the two operators. So, it is recommended to analyse the results of RBT test using some image analysis techniques rather than just relying on naked eye observations. 
Table Error! No text of specified style in document.: Comparison of percentage retained coating between visual observation and Matlab analysis for granite aggregate combinations

\begin{tabular}{|c|c|c|c|}
\hline Time (Hrs) & Sample Name & $\begin{array}{c}\text { Percentage } \\
\text { Coating by } \\
\text { Visual Observation }\end{array}$ & $\begin{array}{c}\text { Percentage } \\
\text { Coating by } \\
\text { Matlab }\end{array}$ \\
\hline 6 & 40-60 Bitumen & 80 & 70 \\
\hline 24 & 40-60 Bitumen & 30 & 25 \\
\hline 48 & 40-60 Bitumen & 10 & 15 \\
\hline 72 & 40-60 Bitumen & 5 & 10 \\
\hline 6 & $50 \% \mathrm{G}$ & 80 & 80 \\
\hline 24 & $50 \% \mathrm{G}$ & 50 & 70 \\
\hline 48 & $50 \% \mathrm{G}$ & 40 & 40 \\
\hline 72 & $50 \% \mathrm{G}$ & 25 & 35 \\
\hline 6 & $40 \% \mathrm{G}+10 \% \mathrm{HL}$ & 90 & 80 \\
\hline 24 & $40 \% \mathrm{G}+10 \% \mathrm{HL}$ & 65 & 75 \\
\hline 48 & $40 \% \mathrm{G}+10 \% \mathrm{HL}$ & 60 & 60 \\
\hline 72 & $40 \% \mathrm{G}+10 \% \mathrm{HL}$ & 50 & 55 \\
\hline 6 & $30 \% \mathrm{G}+20 \% \mathrm{HL}$ & 90 & 80 \\
\hline 24 & $30 \% \mathrm{G}+20 \% \mathrm{HL}$ & 70 & 80 \\
\hline 48 & $30 \% \mathrm{G}+20 \% \mathrm{HL}$ & 60 & 65 \\
\hline 72 & $30 \% \mathrm{G}+20 \% \mathrm{HL}$ & 60 & 55 \\
\hline
\end{tabular}


Table 5: Comparison of percentage retained coating between visual observation and Matlab analysis for limestone aggregate combinations

\begin{tabular}{|c|c|c|c|}
\hline Time (Hrs) & Sample Name & $\begin{array}{c}\text { Percentage } \\
\text { Coating by } \\
\text { Visual Observation }\end{array}$ & $\begin{array}{c}\text { Percentage } \\
\text { Coating by } \\
\text { Matlab }\end{array}$ \\
\hline 6 & 40-60 Bitumen & 85 & 75 \\
\hline 24 & 40-60 Bitumen & 60 & 65 \\
\hline 48 & 40-60 Bitumen & 50 & 60 \\
\hline 72 & 40-60 Bitumen & 45 & 55 \\
\hline 6 & $50 \% \mathrm{LS}$ & 90 & 85 \\
\hline 24 & $50 \% \mathrm{LS}$ & 80 & 80 \\
\hline 48 & $50 \% \mathrm{LS}$ & 70 & 70 \\
\hline 72 & $50 \% \mathrm{LS}$ & 60 & 60 \\
\hline 6 & $40 \% \mathrm{LS}+10 \% \mathrm{HL}$ & 80 & 80 \\
\hline 24 & $40 \% \mathrm{LS}+10 \% \mathrm{HL}$ & 70 & 70 \\
\hline 48 & $40 \% \mathrm{LS}+10 \% \mathrm{HL}$ & 60 & 65 \\
\hline 72 & $40 \% \mathrm{LS}+10 \% \mathrm{HL}$ & 50 & 60 \\
\hline 6 & $30 \% \mathrm{LS}+20 \% \mathrm{HL}$ & 80 & 80 \\
\hline 24 & $30 \% \mathrm{LS}+20 \% \mathrm{HL}$ & 65 & 75 \\
\hline 48 & $30 \% \mathrm{LS}+20 \% \mathrm{HL}$ & 60 & 60 \\
\hline 72 & $30 \% \mathrm{LS}+20 \% \mathrm{HL}$ & 50 & 55 \\
\hline
\end{tabular}


Table 6: Comparison of percentage retained coating between visual observation and Matlab analysis for basalt aggregate combinations

\begin{tabular}{|c|c|c|c|}
\hline Time (Hrs) & Sample Name & $\begin{array}{c}\text { Percentage } \\
\text { Coating by } \\
\text { Visual Observation }\end{array}$ & $\begin{array}{c}\text { Percentage } \\
\text { Coating by } \\
\text { Matlab }\end{array}$ \\
\hline 6 & 40-60 Bitumen & 80 & 80 \\
\hline 24 & 40-60 Bitumen & 60 & 55 \\
\hline 48 & 40-60 Bitumen & 50 & 45 \\
\hline 72 & 40-60 Bitumen & 40 & 35 \\
\hline 6 & $50 \% \mathrm{~B}$ & 90 & 70 \\
\hline 24 & $50 \% \mathrm{~B}$ & 65 & 60 \\
\hline 48 & $50 \% \mathrm{~B}$ & 50 & 45 \\
\hline 72 & $50 \% \mathrm{~B}$ & 40 & 40 \\
\hline 6 & $40 \% \mathrm{~B}+10 \% \mathrm{HL}$ & 90 & 85 \\
\hline 24 & $40 \% \mathrm{~B}+10 \% \mathrm{HL}$ & 70 & 75 \\
\hline 48 & $40 \% \mathrm{~B}+10 \% \mathrm{HL}$ & 65 & 65 \\
\hline 72 & $40 \% \mathrm{~B}+10 \% \mathrm{HL}$ & 60 & 60 \\
\hline 6 & $30 \% \mathrm{~B}+20 \% \mathrm{HL}$ & 95 & 85 \\
\hline 24 & $30 \% \mathrm{~B}+20 \% \mathrm{HL}$ & 80 & 80 \\
\hline 48 & $30 \% \mathrm{~B}+20 \% \mathrm{HL}$ & 70 & 70 \\
\hline 72 & $30 \% \mathrm{~B}+20 \% \mathrm{HL}$ & 65 & 65 \\
\hline
\end{tabular}


Table 7: Comparison of percentage retained coating between visual observation and Matlab analysis for greywacke aggregate combinations

\begin{tabular}{|c|c|c|c|}
\hline Time (Hrs) & Sample Name & $\begin{array}{c}\text { Percentage } \\
\text { Coating by } \\
\text { Visual } \\
\text { Observation }\end{array}$ & $\begin{array}{c}\text { Percentage } \\
\text { Coating by } \\
\text { Matlab }\end{array}$ \\
\hline 6 & 40-60 Bitumen & 95 & 90 \\
\hline 24 & 40-60 Bitumen & 70 & 75 \\
\hline 48 & 40-60 Bitumen & 60 & 55 \\
\hline 72 & 40-60 Bitumen & 50 & 40 \\
\hline 6 & $50 \% \mathrm{GW}$ & 90 & 90 \\
\hline 24 & $50 \% \mathrm{GW}$ & 75 & 70 \\
\hline 48 & $50 \% \mathrm{GW}$ & 60 & 55 \\
\hline 72 & $50 \% \mathrm{GW}$ & 55 & 50 \\
\hline 6 & $40 \% \mathrm{GW}+10 \% \mathrm{HL}$ & 90 & 90 \\
\hline 24 & $40 \% \mathrm{GW}+10 \% \mathrm{HL}$ & 80 & 75 \\
\hline 48 & $40 \% \mathrm{GW}+10 \% \mathrm{HL}$ & 70 & 65 \\
\hline 72 & $40 \% \mathrm{GW}+10 \% \mathrm{HL}$ & 60 & 65 \\
\hline 6 & $30 \% \mathrm{GW}+20 \% \mathrm{HL}$ & 95 & 95 \\
\hline 24 & $30 \% \mathrm{GW}+20 \% \mathrm{HL}$ & 85 & 85 \\
\hline 48 & $30 \% \mathrm{GW}+20 \% \mathrm{HL}$ & 75 & 80 \\
\hline 72 & $30 \% \mathrm{GW}+20 \% \mathrm{HL}$ & 70 & 70 \\
\hline
\end{tabular}


Some of the recent studies on RBT results analysis have reported the difficulties in image analysis with aggregates having a dark colour such as basalt, where the pixels of bitumen coated aggregates appear the same as pixels of dark coloured aggregate $[9,10]$, but no such difficulty in analysis was found using the code produced as a part of this research.
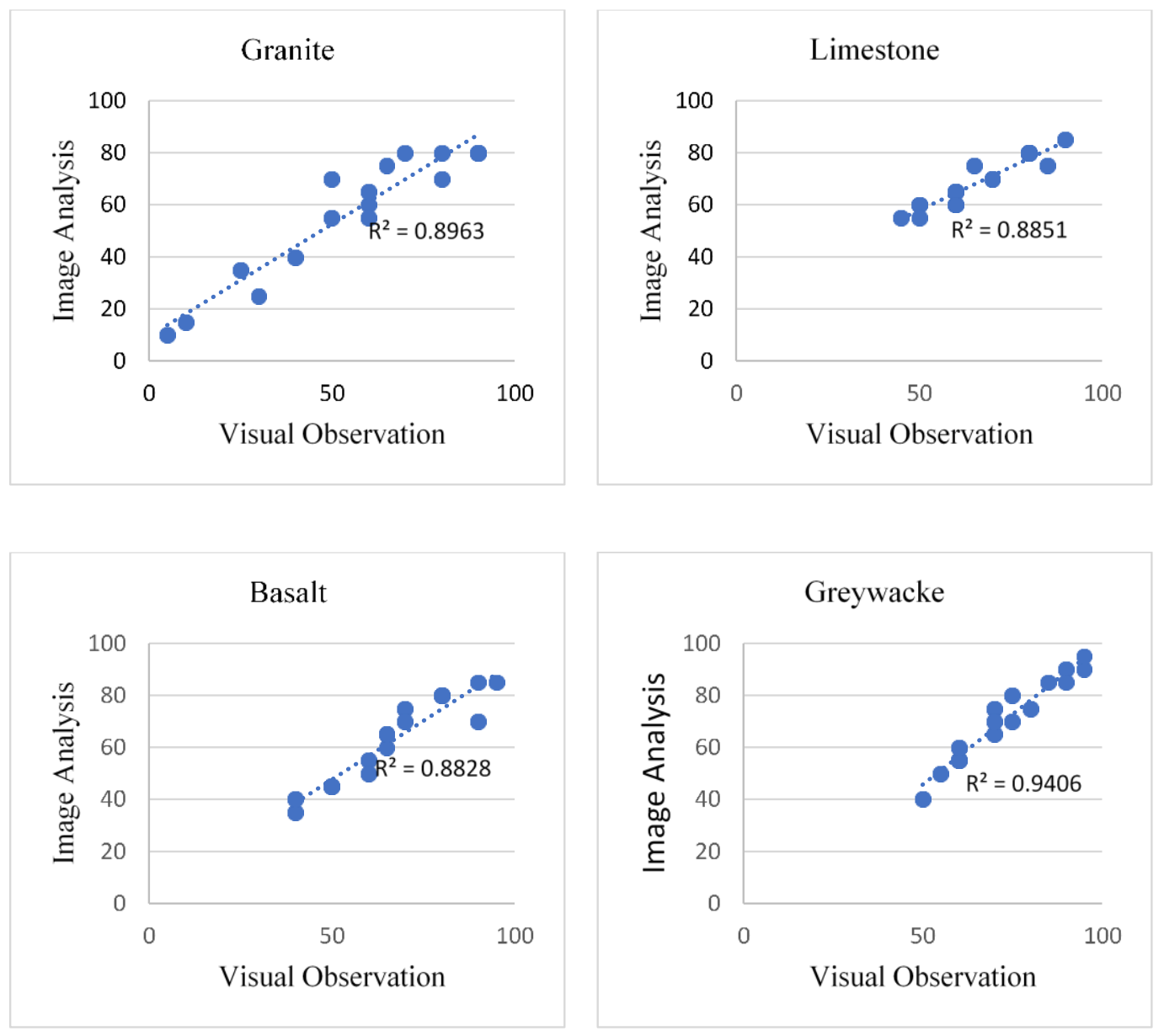

Figure 7: Relationship between visual observation and image analysis results in RBT for all four aggregate types

To further support the statement made above that the results obtained by visual inspection and those computed after image analysis are similar to each other, the results of each aggregate combination obtained by visual inspection have been plotted against results obtained after image analysis and are presented in Figure 7. The R-squared value was calculated for each aggregate type, which is a statistical measure of how close the data are to the fitted regression line. In Figure 7 it can be observed that the R-squared value ranges from 0.88 to 0.94 , which indicates a good fit and so the two results are not far from each other and can be referred to as similar. 

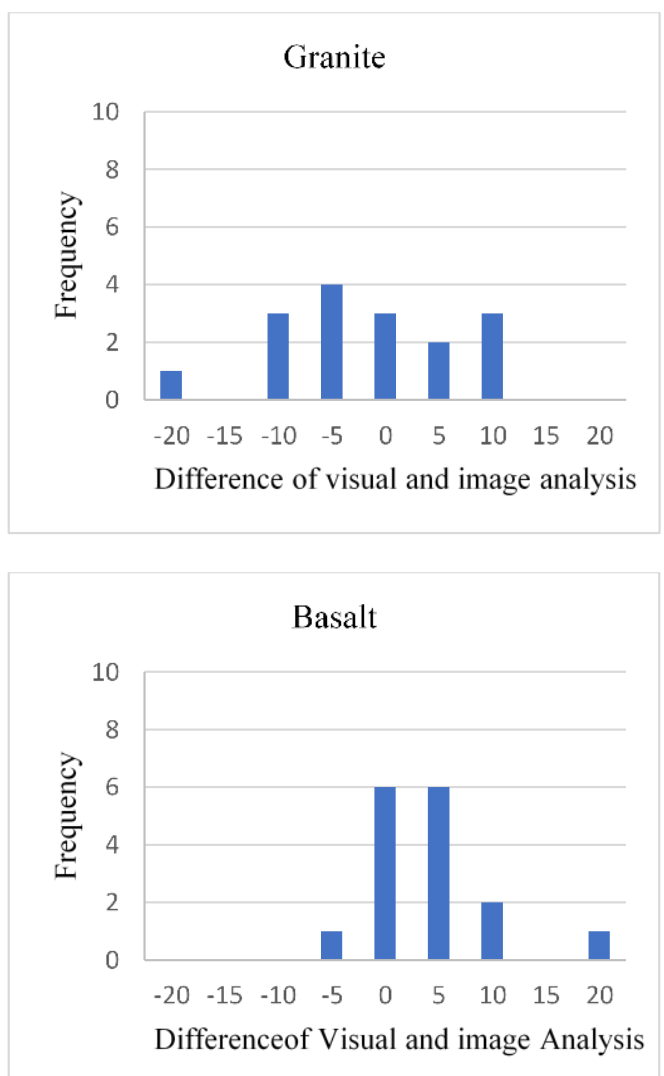
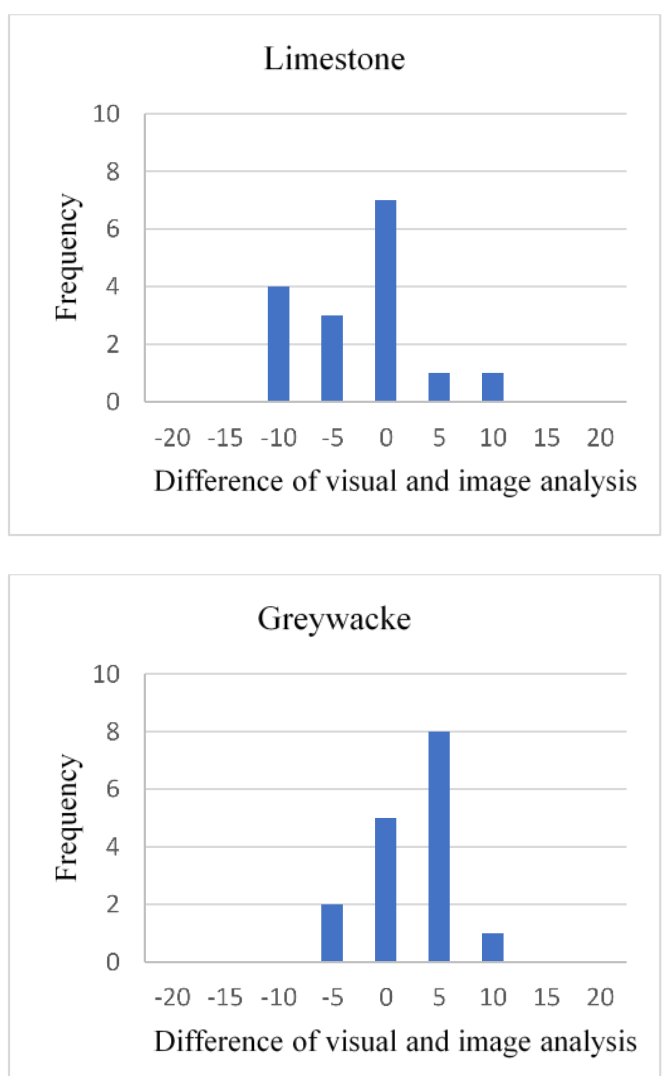

Figure 8: Frequency distribution of the difference between the visual and image analysis results for all the four aggregate types

The frequency distribution of the difference between the visual and image analysis results for all the four aggregate types is shown in Figure 8. By looking carefully at the figure it can be observed that the difference between the visual and image analysis results for most of the aggregate types is within $\pm 10 \%$, so again it is concluded that the visual and image analysis results are similar, but the chance of error in the results computed using image analysis may be less compared to those obtained by visual examination.

\section{Conclusions}

The Rolling bottle test was successfully performed on all the combinations used in this study and was quite useful in discriminating different combinations. An image analysis technique by using Matlab software was used for the calculation of percentage retained coating after $6,24,48$ and 72 hours of agitation. The following conclusions can be drawn based on the results presented in this paper: 
- The results after image analysis were compared to the results of naked eye observation and both were found to be very similar. Hence the RBT can now be used confidently for the comparison of different combinations using image analysis.

- The chances of error in the in the visual inspection can be more so this image analysis technique can replace the visual inspection method hence improving the reliability of rolling bottle test technique.

- The beneficial effects of HL addition were clearly quantified with granite, basalt and greywacke aggregates but limestone aggregates did not respond to the addition of HL when tested in the rolling bottle test.

- A $10 \%$ HL substitution was found to be more efficient compared to $20 \%$ HL substitution, as it gave very similar results in most of the studied combinations.

\section{References}

1. BS EN 12697-11 (2012) bituminous mixtures - test methods for hot mix asphalt - part 11: determination of the affinity between aggregate and bitumen.

2. Airey GD, Choi YK (2002) State of the Art Report on Moisture Sensitivity Test Methods for Bituminous Pavement Materials. International Journal of Road Materials and Pavement Design 3(4), pp. 355-372.

3. Jorgensen T Testing adhesion between bitumen and aggregate with the rolling bottle test and the boiling test. In: PROCEEDINGS OF THE 6TH INTERNATIONAL CONFERENCE ON THE BEARING CAPACITY OF ROADS AND AIRFIELDS, LISBON, PORTUGAL, 24-26 JUNE 2002., 2002.

4. Liu Y, Apeagyei A, Ahmad N, Grenfell J, Airey G (2013) Examination of moisture sensitivity of aggregate-bitumen bonding strength using loose asphalt mixture and physico-chemical surface energy property tests. International Journal of Pavement Engineering:1-14. doi:10.1080/10298436.2013.855312

5. Groenninger J (2008) Computergestuetzte Auswertung von Rolling-BottleTests/Computer aided analysis of Rolling-Bottle-Tests. Strasse Und Autobahn 59 (7)

6. Grönniger J, Wistuba MP, Renken P (2010) Adhesion in bitumen-aggregate-systems: New technique for automated interpretation of rolling bottle tests. Road Materials and Pavement Design 11 (4):881-898

7. Källén $\mathrm{H}$, Heyden $\mathrm{A}$, Lindh $\mathrm{P}$ Measuring bitumen coverage of stones using a turntable and specular reflections. In: 8th International Conference on Computer Vision Theory and Applications (VISAPP 2013), 2013. SciTePress, pp 333-337

8. Porot L, Soenen H, Apeagyei A, Grenfell J, Vansteenkiste S, Chailleux E (2018) Recommendation of RILEM TC 237-SIB on affinity between aggregates and bituminous binders. Materials and Structures 51. doi:10.1617/s11527-018-1297-6

9. Yuan J, Dong W-J, Chen J-J, Zhang S, Qian W-B, Sun W-W (2015) A LED-based measurement system for affinity between bitumen and aggregate. Construction and Building Materials 81:298-302. doi:10.1016/j.conbuildmat.2014.12.066 
10. Lantieri C, Lamperti R, Simone A, Vignali V, Sangiorgi C, Dondi G, Magnani M (2017) Use of image analysis for the evaluation of rolling bottle tests results. International Journal of Pavement Research and Technology 10 (1):45-53. doi:10.1016/j.ijprt.2016.11.003

11. Carl C, Lopes P, Sá da Costa M, Canon Falla G, Leischner S, Micaelo R (2019) Comparative study of the effect of long-term ageing on the behaviour of bitumen and mastics with mineral fillers. Construction and Building Materials 225:76-89. doi:https://doi.org/10.1016/j.conbuildmat.2019.07.150

12. Zaidi SBA (2018) The influence of hydrated lime on moisture susceptibility of asphalt mixtures. University of Nottingham,

13. Roman C, García-Morales M (2018) Comparative assessment of the effect of microand nano- fillers on the microstructure and linear viscoelasticity of polyethylene-bitumen mastics. Construction and Building Materials 169:83-92. doi:https://doi.org/10.1016/j.conbuildmat.2018.02.188

14. Asphalt Task Force (2010) Hydrated Lime: A proven additive for durable asphalt pavements, Critical Literature Review, Report To The European Lime Association / Asphalt Task Force.

15. BS 2000-549 (2007) Bitumen and bituminous binders. Measurement of density and specific gravity. Capillary-stoppered pyknometer method.

16. BS EN 1426 (2000) Methods of tests for petroleum and its products. Bitumen and bituminous binders. Determination of needle penetration.

17. BS 2000-58 (2007) Bitumen and bituminous binders. Determination of the softening point. Ring and Ball method.

18. Hicks RG (1991) Moisture damage in asphalt concrete. vol 175. Transportation Research Board,

19. Bagampadde U, Isacsson U, Kiggundu BM (2004) Classical and contemporary aspects of stripping in bituminous mixes. Road materials and pavement design 5 (1):7-43 